\title{
The Characteristic Analysis of Canopy Spectrum and Moisture Content of 10 Typical Arid Desert Plants
}

\author{
Wei Huaidong ${ }^{1,2}$, Li Jingjing ${ }^{2,}$, Chen Fang ${ }^{2}$, Zhang Bo ${ }^{1}$, Zhou Lanping ${ }^{2}$, Li Ya ${ }^{2}$, Yang Xuemei ${ }^{2}$ \\ ${ }^{1}$ Collage of Geography and Environmental Science, Northwest Normal University, Lanzhou, China \\ ${ }^{2}$ The State Key Laboratory Breeding Base of Desertification and Aeolian Sand Disaster Combating of Gansu Desert Control Research Institute, \\ Lanzhou, China
}

Email address:

weihdgs@126.com (Wei Huaidong), jingjing890520@sina.com (Li Jingjing)

${ }^{*}$ Corresponding author

To cite this article:

Wei Huaidong, Li Jingjing, Chen Fang, Zhang Bo, Zhou Lanping, Li Ya, Yang Xuemei. The Characteristic Analysis of Canopy Spectrum and Moisture Content of 10 Typical Arid Desert Plants. Journal of Energy and Natural Resources. Vol. 8, No. 1, 2019, pp. 6-11.

doi: $10.11648 /$ j.jenr.20190801.12

Received: January 7, 2019; Accepted: March 7, 2019; Published: March 8, 2019

\begin{abstract}
Plant water is a main factor to affect physiological and biochemical indexes of plants like photosynthesis, respiration, and biomass and so on. The investigation of plant water content is an important part of vegetation research. The study of the relationship between water content and canopy spectrum of typical desert plants by hyper spectral has great significance for remote sensing monitoring of vegetation in arid desert areas. The canopy spectral curves of 10 typical desert plants were determined by ASD portable ground spectrometer in this study. The correlation coefficient method and vegetation index method were used to analyze the spectral characteristics of different desert plants and their relationship with canopy moisture content. The results show: 1) the reflectance curve of desert plants has the general characteristics of green plants in the visible-near-infrared band, with obvious "green peak" characteristics and "red edge effect". 2) In the three wavebands of 954-973 $\mathrm{nm}, 1184-1198 \mathrm{~nm}$ and 1440-1462 nm, desert plants have obvious water absorption valleys. Among them, the correlation coefficient between spectral reflectance and water content in the $1440-1462 \mathrm{~nm}$ band is greater than 0.8 , and they have strong linear correlation. 3) WBI (Water Band Index), NDWI (Normalized Difference Water Index), NDII (Normalized Difference Infrared Index), MSI (Moisture Stress Index) were significantly correlated with plant water content $(\mathrm{P}<0.05)$, and the measured values of canopy moisture content index and vegetation moisture have high consistency and can reflect the change of moisture content of desert vegetation.
\end{abstract}

Keywords: Spectral Characteristics, Plant Water Content, Correlation Coefficient, Canopy Moisture Content Index, Desert Plant, Minqin

\section{Introduction}

The natural environment of the desert area is bad. The desert vegetation is preserved by cruel natural selection. They adapt to harsh ecological conditions in various physiological and ecological ways. Although they grow sparsely in the desert, they are the primary producers of the desert ecosystem and important factors for maintaining the stability of the desert ecosystem, and occupying an absolutely important ecological status in the desert ecosystem [1]. Plant water is one of the main factors affecting plant photosynthesis, respiration, biomass and other physiological and biochemical indicators.
The investigation of plant water content is an important part of vegetation research. To understand the water status of large-scale desert plants, the use of traditional sampling methods is not only time-consuming and labor-intensive, but also the results of surveys are often only point-like or linear breakpoint information, which cannot achieve continuous time-series information collection, and the representation is also questioned. Hyperspectral remote sensing is an effective method for vegetation moisture monitoring. The analysis and inversion of plant water content based on hyperspectral data can provide an effective way for large-area plant moisture monitoring [2-3].

Zhao Wei used correlation coefficient method to analyze the 
relationship between plant moisture content and reflectance spectrum. The results show that the near-infrared 1374-1534 $\mathrm{nm}$ band reflectance spectrum has the best correlation with plant water content, which is the characteristic band for expressing plant water content [4-5]. Wang Penglong et al [6] analyzed the relationship between the typical plant moisture content and the spectral spectrum in Tengger Desert and found that the moisture content and the spectral data with envelope removal were significantly correlated in the visible and near-infrared bands. These studies show that the reflectance spectrum can reflect the change of moisture content of desert plants, and hyperspectral remote sensing can be used to analyze the moisture content of desert vegetation. In this study, 10 typical xerophytes widely distributed in the desert area of Hexi Corridor were studied. The canopy spectra were measured in the field, and the spectral response characteristics of desert plants moisture content were studied by correlation coefficient method and spectral index. The aim is to provide basis for vegetation remote sensing information extraction in arid region.

\section{Data and Methods}

\subsection{Overview of the Study Area}

The field test area for the collection of desert plants is located in the eastern part of the Hexi Corridor, the oasis-desert transition zone of Minqin County in the lower reaches of the Shiyang River Basin. The geographical location is $101^{\circ} 41^{\prime}-104^{\circ} 16^{\prime} \mathrm{E}, 36^{\circ} 29^{\prime}-39^{\circ} 27$ 'N. The study area is a temperate continental arid climate. The annual average temperature is $8{ }^{\circ} \mathrm{C}$, and the annual average precipitation is less than $150 \mathrm{~mm}$. Controlled by the typical arid desert climate the zonal vegetation in the study area is mainly composed of super-dry shrubs, semi-shrub deserts and super-slung semi-ary deserts. The plant species are few, the layer structure is simple, and the productivity is low [7]. The natural vegetation in the study area can be divided into gravel desert vegetation, sandy desert vegetation and salinized meadow vegetation according to landform, soil and vegetation characteristics. Among them, the gravel desert vegetation is mainly distributed in the low mountains, the denuded mounds and the gravel Gobi area. The main plants are Salsola passerina, Reaumuria songarica and Nitraria sphaerocarpa etc. Sandy desert vegetation is mainly distributed in flat sand, sand ridges and sand dunes and low hills. Vegetation consists of sandy shrubs, semi-shrubs and annual and perennial herbs. Degraded meadow vegetation is mainly composed of leafy drought-tolerant or salt-loving vegetation, such as Kalidium foliatum, Suaeda salsa, and Phragmites australis. Due to the intersection of the two desert of Tengger and Badain Jilin, the problem of land desertification is very serious, and desertified land accounts for more than $90 \%$ of the total area. This study selected Zygophyllum xanthoxylon, Nitraria tanggutorum, Ajania fruticulosa, Sympegma regelii, Lycium ruthenicum Murr, Artemisia desertorum, Kalidium foliatum, Artemisia ordosica, Salsola passerine, Kareliniacaspia ten species widely distributed in the arid desert region as spectral characterization study objects.

\subsection{Data Collection}

\subsubsection{Spectral Data Acquisition}

Plant spectral data was measured by an ASD (analytical spectral devices) Field spec4 portable spectrometer with a reflectance range of 350-2500 nm, a spectral sampling interval of approximately $1.5 \mathrm{~nm}$, and a spectrometer probe field of view angle of $25^{\circ}$. The wild plant spectral collection time is from July 24th to August 1st, 2017, and the spectrum is collected during the 10:00-14:00 period of direct sunlight. When measuring, the spectrometer probe is placed vertically about $20 \mathrm{~cm}$ above the vegetation canopy, and the plant is measured downwards to ensure that the plant under test fills the entire field of view.

According to the growth characteristics of each plant, the concentrated area of the plant was selected as the research plot, and 20 plants with good growth and similar background were selected in the plot to perform spectral measurement as samples. Five spectral curves were acquired per sample per time. The whiteboard calibration is performed before each spectrum acquisition, and the whiteboard calibration is performed again every 5 to 10 minutes. Because the field spectrometer is greatly affected by the environment, the original spectral data is screened. By checking the spectral data and spectral curve of the measured object and the standard plate, the invalid data is removed to ensure the effectiveness of spectral data [8].

\subsubsection{Canopy Moisture Data Collection}

The plant canopy moisture content was sampled while measuring the wild plant spectral curve of the desert plant. Each desert plant chooses to grow healthy plants, use scissors to cut the fresh leaves of the plants in the same year, put them into the sealed pockets, and immediately call the fresh weight. Labeled and brought back to the lab. Plant moisture content data was obtained in the laboratory by dry weighing.

\subsection{Data Processing}

The curve obtained by the external observations of the View SpecPro spectral data analysis software was screened to remove the abnormal curve, and the normal curve of the same kind of plants was averaged to represent the spectral curve data of the plant. Convert the original curve $\mathrm{DN}$ value to a spectral reflectance value. On this basis, the correlation coefficient method and vegetation index method were used to analyze the response characteristics of desert plant spectrum to water content change.

\subsubsection{Correlation Coefficient Method}

The correlation coefficient is an indicator used to measure the degree of linear correlation between two random variables. It was proposed by Karl Pearson in 1880 and is calculated as follows: 


$$
r_{x y}=\frac{\sum_{i=1}^{n}\left(x_{i}-\bar{x}\right)\left(y_{i}-\bar{y}\right)}{\sqrt{\sum_{i=1}^{n}\left(x_{i}-\bar{x}\right) \sum_{i=1}^{2}\left(y_{i}-\bar{y}\right)^{2}}}
$$

Among them, $r_{x y}$ is the correlation coefficient between the moisture content of desert plants and the spectral reflectance of desert plants. $\bar{X}$ and $\bar{y}$ are the mean value of desert plant water content and desert plant spectral reflectance. $x$ and $y$ are respectively the desert plant moisture content and the observation value of the i-band of spectral reflectance of desert plant. $\mathrm{n}$ is the total number of samples. The correlation coefficient has a value range of $[-1,1], r>0$ indicates a positive correlation, $\mathrm{r}<0$ indicates a negative correlation, and $|\mathrm{r}|$ indicates the degree of correlation between variables. Usually, when $|r|$ is greater than 0.8 , the two variables are considered to have a strong linear correlation [9-10].

\subsubsection{Vegetation Index Method}

The canopy moisture content index is used to measure the moisture content in the vegetation canopy. It is based on the absorption characteristics of water in the near-infrared and short-wave infrared range and the penetration of light in the near-infrared range [11]. In this study, four kinds of the most commonly used canopy moisture content index were selected to study the vegetation water content. The calculation formula of the selected vegetation index is shown in Table 1 .

Table 1. Canopy moisture content index.

\begin{tabular}{lll}
\hline Index name & Expression form & Basic description \\
\hline WBI & WBI $=\mathrm{R}_{900} / \mathrm{R}_{970}$ & The measured absorption intensity at 900 nm increases as the canopy water volume increases. \\
NDWI & $\mathrm{NDWI}=\left(\mathrm{R}_{875}-\mathrm{R}_{1241}\right) /\left(\mathrm{R}_{875}+\mathrm{R}_{1241}\right)$ & $\begin{array}{l}\text { Measure the increase in absorption of vegetation moisture at } 857 \mathrm{~nm} \text { relative to the absorption at } \\
1241 \mathrm{~nm}\end{array}$ \\
NDII & $\mathrm{NDII}=\left(\mathrm{R}_{819}-\mathrm{R}_{1649}\right) /\left(\mathrm{R}_{819}+\mathrm{R}_{1649}\right)$ & $\begin{array}{l}\text { Monitoring changes in vegetation moisture at } 1599 \mathrm{~nm} \\
\text { MSI }\end{array}$ \\
\hline
\end{tabular}

\section{Results and Discussion}

\subsection{Determination of Moisture Content of Desert Plants}

The results of water measurement of 10 desert plants in the study area showed that the canopy moisture content of desert plants was different during the survey period. The smallest water content was Ajania fruticulosa, the canopy moisture content was only $18.53 \%$, and the largest water content was Kareliniacaspia and the moisture content was 71.17\% (Figure 1).

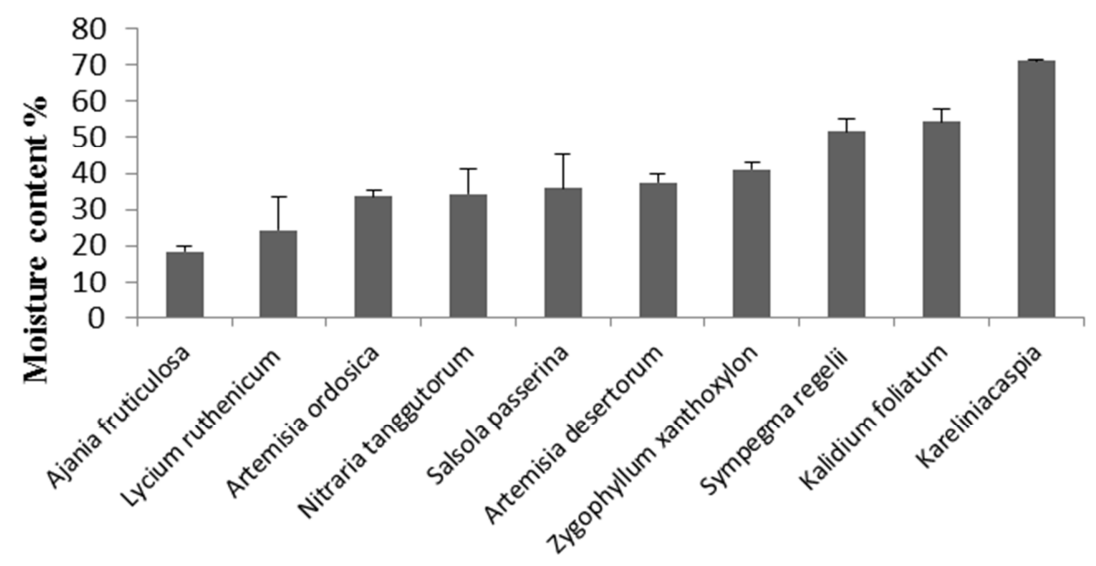

Figure 1. Water containing ratio of 10 desert vegetation.

\subsection{Basic Characteristics of Desert Plant Spectrum}

The reflection spectra of 10 desert plants have the general characteristics of green plants in the visible-near-infrared band [12-18]. The first peak appeared near the green wavelength of $550 \mathrm{~nm}$ at $400-760 \mathrm{~nm}$ visible light, but the peak was not high, and most of the plants had a reflectance around 0.1 . This region is a typical reflection spectrum characteristic of green plants, showing strong reflection of chlorophyll on green light; the reflectivity of 550-680 $\mathrm{nm}$ gradually decreases, and the degree of reduction is also low (Figure 2). There is strong absorption near the red light band of $680 \mathrm{~nm}$, forming the first absorption valley. The main solar spectrum in this region is red, which is the strongest absorption range of plant photosynthesis; in the near infrared, 10 kinds of desert plant spectral curve suddenly increases in reflectivity at $670-760 \mathrm{~nm}$, forming a plant-specific red edge effect. Therefore, in the visible light band, except for the high reflectance of the red light wavelength range, the spectral reflectance of the other wavelength bands is very low, and the plant has a strong absorption capacity for light. 


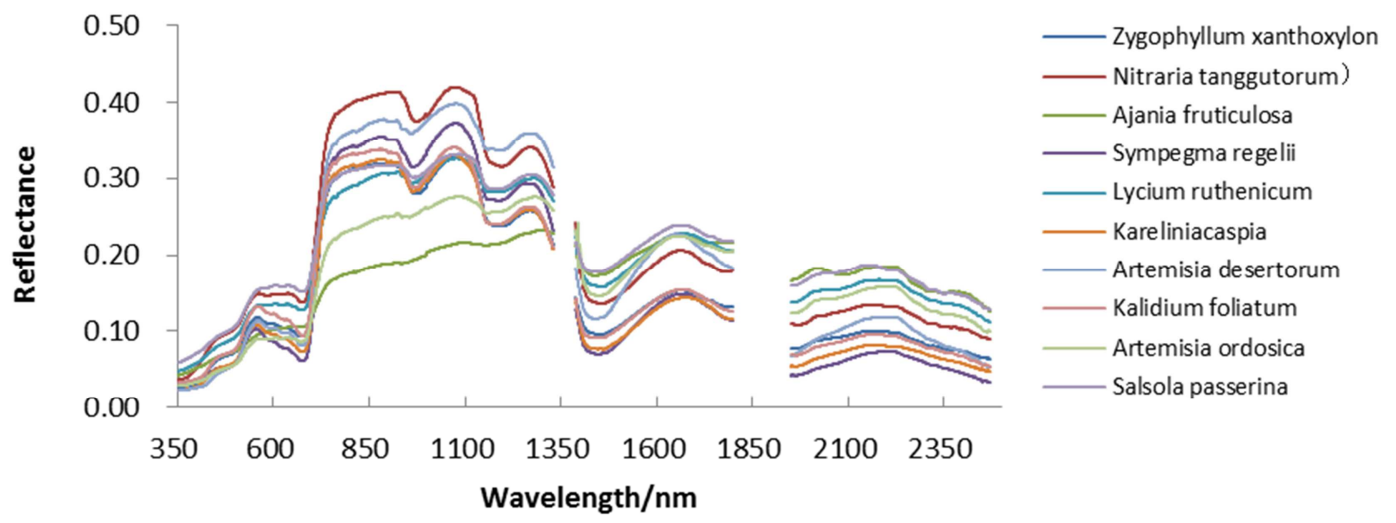

Figure 2. Shrub vegetation spectral characteristic curve.

\subsection{Desert Plant Spectrum and Plant Canopy Moisture Content}

\subsubsection{Plant Canopy Moisture Content Spectral Expression Characteristic Band}

Many studies have shown that in the near-infrared and short-wave infrared bands, there are five leaf moisture absorption bands centered at 970, 1 200, 1 450, 1930 and 2 $500 \mathrm{~nm}[4,11]$. It can be seen from Figure 2 that all desert plants have obvious absorption valleys in the three bands of 954-973 nm, 1 184-1 $198 \mathrm{~nm}$ and 1 440-1 $462 \mathrm{~nm}$. This

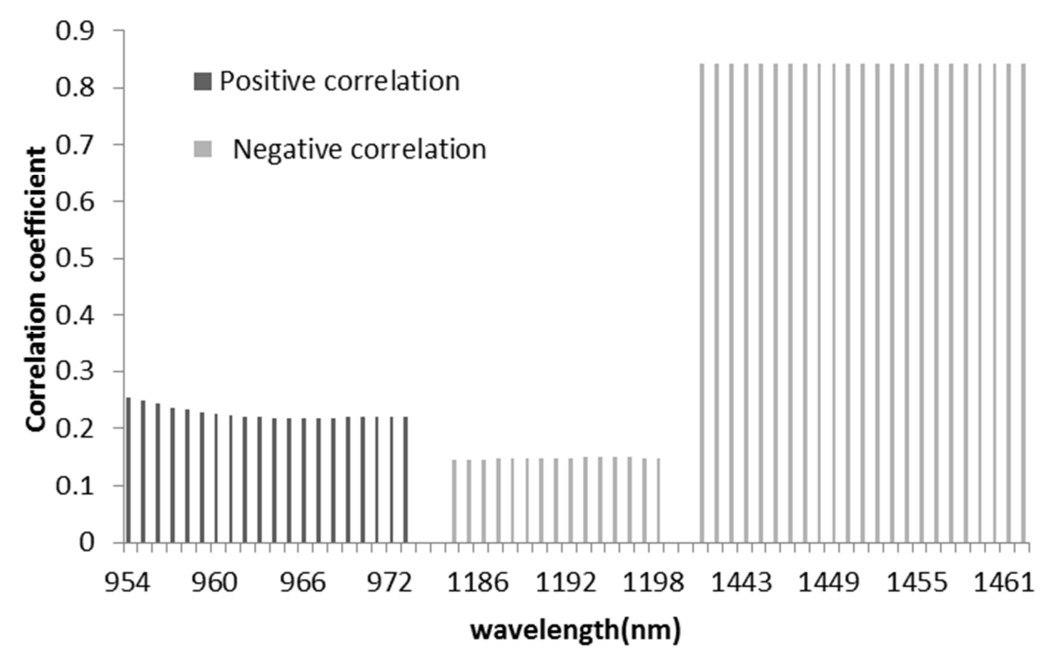

spectrum is measured in the field. In the range of 1930 and 2 $500 \mathrm{~nm}$, it is affected by water vapor absorption and the instruments' own noise. The data is noisy and is not suitable for further research.

\subsubsection{Correlation Analysis Between Spectral Reflectance and Water Content of Plants}

Based on the correlation coefficient method, the laboratory measured water content of desert plants was correlated with the spectral reflectance of three water-sensitive bands of 954-973 nm, 1184-1198 nm and 1 440-1 $462 \mathrm{~nm}$ (Figure 3).
Figure 3. Correlation coefficient between reflectivity and water conte
It can be seen that in the $954-973 \mathrm{~nm}$ range, the water content and the reflectivity are positive correlation. The maximum correlation coefficient is 0.253 and the minimum is 0.217 . The correlation is general. In the $1184-1198 \mathrm{~nm}$ band, the spectral reflectance and water content are negative correlation, the correlation coefficient is between 0.145 and 0.149 , and the correlation is poor. In the $1440-1462 \mathrm{~nm}$ band, there was a significant negative correlation between plant water content and spectral reflectance $(\mathrm{P}<0.05)$, and the correlation coefficient was $0.840-0.842$.

\subsubsection{Canopy Moisture Content Index and Water Content}

The spectral characteristics of desert plants were further analyzed by four bands of WBI, NDWI, NDII and MSI. Among the four indexes, the larger of the values of the first three plants by the index WBI, NDWI, NDII, the water content is more. While MSI is the opposite, and the MSI value is larger, the water stress is more serious and the water content is higher. Among the four indexes, Ajania fruticulosa had the lowest water content, so the canopy moisture content index WBI, NDWI, NDII were lower than other plants, and the MSI value was higher than other plant species (Table 2). The values of WBI, NDWI and NDII of Kalidium foliatum and Kareliniacaspia were higher than other plants, and the MSI value was lower than other plant species. 
Table 2. Canopy moisture content index of 10 desert plants.

\begin{tabular}{lllll}
\hline \multirow{2}{*}{ Plant species } & \multicolumn{2}{l}{ Canopy moisture content index } & NDII & MSI \\
\cline { 2 - 5 } & WBI & NDWI & 0.35 & 0.45 \\
\hline Zygophyllum xanthoxylon & 1.14 & 0.11 & 0.33 & 0.47 \\
Nitraria tanggutorum & 1.10 & 0.1 & -0.12 & 1.21 \\
Ajania fruticulosa & 0.97 & -0.1 & 0.4 & 0.39 \\
Sympegma regelii & 1.11 & 0.1 & 0.13 & 0.73 \\
Lycium ruthenicum & 1.03 & 0.01 & 0.38 & 0.41 \\
Kareliniacaspia & 1.13 & 0.12 & 0.23 & 0.58 \\
Artemisia desertorum & 1.03 & 0.03 & 0.37 & 0.43 \\
Kalidium foliatum & 1.16 & 0.13 & 0.02 & 0.9 \\
Artemisia ordosica & 0.98 & -0.05 & 0.13 & 0.73 \\
Salsola passerina & 1.05 & 0.03 & $0.788^{* *}$ & $-0.761^{*}$ \\
Correlation coefficient & $0.75^{*}$ & $0.759^{*}$ & & \\
\hline
\end{tabular}

Note: ${ }^{*} \mathrm{P}<0.05,{ }^{* *} P<0.01$

Correlation analysis between canopy moisture content index and water content showed that there was a significant positive correlation between WBI, NDWI values and water content values $(\mathrm{P}<0.05)$, and Pearson correlation coefficients were 0.758 and 0.759 respectively. There was significant negative correlation between MSI value and water content value $(\mathrm{P}<0.05)$, and the Pearson correlation coefficient was -0.761 . There was significant positive correlation between NDII value and the water content value $(\mathrm{P}<0.01)$, and the Pearson correlation coefficient was 0.788 . It can be seen that the correlation between the four canopy moisture content indices and water content has reached a significant correlation level, and in the four indices, the correlation between NDII and water content is slightly higher than other three indices. For desert vegetation, the canopy moisture content index has a high consistency with the measured value of vegetation water, which can reflect the change of desert vegetation moisture content.

\section{Conclusions}

The spectral curves of 10 different desert plants were measured by portable spectrometer. The spectroscopic characteristics of the plants were analyzed by means of View SpecPro spectral data analysis software, SPSS and Excel 2007 software. The correlation between spectra of desert plants and water content was analyzed by correlation coefficient and vegetation index. The results show that the desert plant reflectance spectrum has the common characteristics of green plants in the visible-near-infrared band, with obvious "green peak" characteristics and "red edge effect". Correlation analysis between canopy spectral reflectance and water content of desert plants showed that the correlation coefficient between spectral reflectance and water content was higher than 0.8 in the $1440-1462 \mathrm{~nm}$ band, and the two had strong linear correlation. This is basically consistent with the results of the correlation analysis between the moisture content and the reflectance spectrum of 17 species of desert plants in Gurbantunggut bu Zhao Zhao. It can be seen that for desert plants, the leaf water absorption zone centered on $1450 \mathrm{~nm}$ is the most sensitive band reflecting the change of moisture content of desert plants.
It is worth noting that in the course of this study, all desert plant spectra were measured under natural conditions in the field. Due to the sparse distribution of the natural environment and the desert vegetation itself, the spectral data was strongly influenced by the soil and the surrounding environment, and there was a large noise [16-17]. This study only conducted a preliminary analysis of the correlation between moisture content and reflectance spectrum of desert plants. To objectively detect the growth and water status of desert plants, a large number of field experiments and comparative analysis of indoor spectral data are needed to reduce and eliminate the interference of non-deterministic environmental factors in field spectral observations, so that the measured data can truly reflect the desert. The spectral characteristic of desert plants, which also is the main content in further research.

\section{Fund Project}

National Natural Science Foundation of China (31360204, 51579102); Natural Science Foundation of Gansu Province (17JR5RA062).

\section{References}

[1] Zhou L P, Wei H D, Ding F, Chen F, Hu X K. Analysis on spectral reflectance characteristics of desert plants in Minqin Basin of Shiyang River. Journal of Arid Land Resources and Environment, 2013, 27 (3): 121-125. (in Chinese)

[2] Tong Q X, Zhang B, Zheng L F. Hyperspectral Remote Sensing: Principle, Technology and Application. Beijing: Higher Education Press, 2006. (in Chinese)

[3] $\mathrm{Pu} \mathrm{R} \mathrm{L,} \mathrm{Gong} \mathrm{P.} \mathrm{Hyperspectral} \mathrm{Remote} \mathrm{Sensing} \mathrm{and} \mathrm{Its}$ Application. Beijing: Higher Education Press, 2000. (in Chinese)

[4] Zhao Z, Li X, Yin Y B, Zhou S B. Analysis of spectral features based on water content of desert vegetation. Spectroscopy and Spectral Analysis, 2010, 30 (9): 2500-2503. (in Chinese)

[5] Zhao Z. Analysis of Spectral Features Based on Water Content of Xinjiang Desert Plants. Master Thesis. Urumqi: Xinjiang Agricultural University, 2011. (in Chinese) 
[6] Wang P L, Zhang J M, Zhang C M, Xu M S, Wang L. The relationships between spectral features and water content of the dominat plant species in the Tengger Desert. Journal of Desert Research, 2013, 33 (3): 737-742. (in Chinese)

[7] Xu X Y, Ding G D, Sun B P, Zhao M, Jin H X. Ecological water requirement of major sand shifting control forests in Minqin Oasis of lower reaches of inland river. Journal of Soil and Water Conservation, 2007, 21 (3): 144-148. (in Chinese)

[8] Xia X W, Jin G L, An S Z, Fan Y M, Liang N. Spectral characteristics of typical plants in Seriphidium transiliense desert grassland under enclosure. Pratacultural Science, 2015, 32 (6): 870-876. (in Chinese)

[9] Wan Y Q, Yan Y Z, Zhang F L. Analyses to spectral character of the vegetation along Yanhe River. Remote Sensing for Land \& Resources, 2001, 49 (3): 15-20. (in Chinese)

[10] Fuan T, William P. Derivative analysis of hyperspectral data. Remote Sensing of Environment, 1998, 66 (1): 41-51.

[11] Wang Q, Yi Q X, Bao A M, Zhao J. Discussion on hyperspectral index for the estimation of cotton canopy water content. Spectroscopy and Spectral Analysis, 2013, 33 (2): 507-512. 9. (in Chinese)

[12] Wei X H, Jin G L, Fan Y M, An S Z, Xia X W. Species analysis and identification of spectral characteristics on Seriphidium transiliense desert grassland. Pratacultural Science, 2016, 33 (10): 1924-1932. (in Chinese)

[13] Zhang B, Niu T, Fang S F, Wu D Y. Research on the spectral characteristic of typical vegetation in desert-oasis crisscross zone. Spectroscopy and Spectral Analysis, 2016, 36 (4): 1104-1108. (in Chinese)

[14] Lin C, Gong Z N, Zhao Y J. Hyperspectral estimation models for plant community water content at both leaf and canopy levels in Wild Duck Lake wetland. Acta Ecologica Sinica, 2011, 31 (22): 6645-6658. (in Chinese)

[15] Ding J L, Zhang F, Tashpolat T. Research on the spectral character of vegetation in arid area. Journal of Arid Land Resources and Environment, 2008, 22 (11): 160-165. (in Chinese)
[16] Cheng Y L, Wang Z J, Hong J M. Analysis of spectral characteristics on different coverage of Hemarthria altissima in Yeyahu Wetland. Journal of Capital Normal University: Natural Sciences Edition, 2013, 34 (6): 16-21. (in Chinese)

[17] Li Z Z, Zheng X, Niu D K, Guo X M, Xie B Y, Zhang X L. The study on hyperspectral characteristics of main community types in mountain meadow. Pratacultural Science, 2016, 33 (8): 1492-1501. (in Chinese)

[18] Duan R L, Liu Y X, Zhang S W, Duan L M, Tian J. Matching of Spectral data of typical vegetation on dune in the Horqin Sanddy Land. Arid Zone Research, 2014, 31 (4): 750-755. (in Chinese)

[19] Feng X W, Chen X, Bao A M, Sun L, Wang D W, Ma Y Q. Analysis on the cotton physiological change and its hyperspectral response under the water stress conditions. Arid Land Geography, 2004, 27 (2): 250-255. (in Chinese)

\section{Biography}

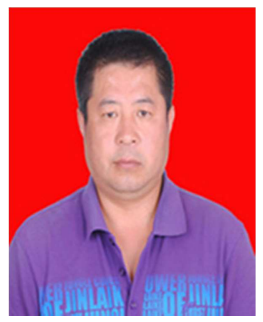

Wei Huaidong (1972.3-) is researcher, born in Jingtai, Gansu, China. He works in Gansu Desert Control Research Institute State Key Laboratory Breeding Base of Desertification and Aralian Sand Disaster Combating in Gansu Province. He is committed to work on remote sensing monitoring of desertification in arid regions and has hosted 3 National Natural Science Foundation projects.

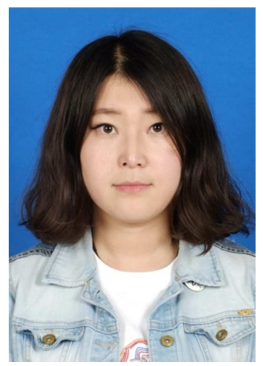

Li Jingjing (1989.5-) is engineer, born in Lanzhou, Gansu, China. She works in Gansu Desert Control Research Institute State Key Laboratory Breeding Base of Desertification and Aralian Sand Disaster Combating in Gansu Province. She is engaged in Desertification control. 